\title{
Point-defects assisted Zn-diffusion in AlGaInP/GaInP systems during the MOVPE growth of inverted multijunction solar cells
}

\author{
Manuel Hinojosa, Iván García*, Shabnam Dadgostar ${ }^{2}$ and Carlos Algora ${ }^{1}$ \\ ${ }^{1}$ Instituto de Energía Solar - Universidad Politécnica de Madrid; ${ }^{2}$ OptronLab - Universidad de Valladolid
}

*igarcia@ies.upm.es

\begin{abstract}
We investigate the dynamics of $\mathrm{Zn}$ diffusion in MOVPE-grown AIGaInP/GaInP systems by the comparison of different structures that emulate the back-surface field (BSF) and base layers of a GaInP subcell integrated into an inverted multijunction solar cell structure. Through the analysis of secondary ion mass spectroscopy (SIMS), electrochemical capacitance-voltage (ECV) and spectrally resolved cathodoluminescence (CL) measurements, we provide experimental evidence that 1 ) the $\mathrm{Zn}$ diffusion is enhanced by point defects injected during the growth of the tunnel junction cathode layer; 2) the intensity of the process is determined by the cathode doping level and it happens for different cathode materials; 3) the mobile $\mathrm{Zn}$ is positively charged and 4) the diffusion mechanism reduces the CuPt ordering in GaInP. We demonstrate that using barrier layers the diffusion of point defects can be mitigated, so that they do not reach $\mathrm{Zn}$-doped layers, preventing its diffusion. Finally, the impact of $\mathrm{Zn}$ diffusion on solar cells with different $\mathrm{Zn}$-profiles is evaluated by comparing the electrical I-V curves at different concentrations. The results rule out the introduction of internal barriers in the BSF but illustrate how $\mathrm{Zn}$ diffusion under typical growth condition can reach the emitter and dramatically affect the series resistance, among other effects.
\end{abstract}

Keywords-III-V epitaxy, Zinc diffusion, III-V multijunction solar cells

\section{INTRODUCTION}

Zinc $(\mathrm{Zn})$ is the most common p-type dopant element in III-V materials grown by metal-organic-vapor-phase-epitaxy (MOVPE). However, $\mathrm{Zn}$ has proved to be a strong and rapid diffuser, which complicates the achievement of intended doping profiles and can spoil the optoelectronic performance of a variety of devices such as bipolar junction transistors (BJT), light-emitting diodes (LED), lasers or multijunction solar cells (MJSC) [1][2][3][4][5]. Previous investigations revealed that the n-type doping of nearby layers enhances the Zn diffusion process [6][7]. Particularly, the widely accepted model proposed for an AlGaAs/GaAs system by Deppe et al. suggests that the Fermi level pinning at the surface during the growth of a heavily doped n-type GaAs leads to an imbalance and injection of group-III interstitials $\left(\mathrm{Ga}_{\mathrm{I}}\right)$ [8]. According to the model, the injected defects diffuse rapidly from the surface to buried layers, where active $\mathrm{Zn}$ is located in the group-III site of the lattice $\left(\mathrm{Zn}_{\mathrm{Ga}}{ }^{-}\right)$, and promotes the so-called kick-out process. This way, $\mathrm{Ga}_{\mathrm{I}}$ transfers $\mathrm{Zn}$ to an interstitial position $\left(\mathrm{Zn}_{\mathrm{I}}\right)$ and reduces the local concentration of holes $\left[\mathrm{h}^{+}\right]$. Finally, the interstitial $\mathrm{Zn}$ diffuses, and the reverse process takes place via Frenkel mechanisms, releasing new $\mathrm{Ga}$ interstitials.

$$
\mathrm{Ga}_{\mathrm{I}}+\mathrm{Zn}_{\mathrm{Ga}}{ }^{-}+\mathrm{h}^{+} \leftrightarrow \mathrm{Ga}_{\mathrm{Ga}}+\mathrm{Zn}_{\mathrm{I}}
$$

Thus, the growth of a highly n-doped layer on the top of a $\mathrm{Zn}$-doped $\mathrm{AlGaInP/GaInP}$ system is expected to induce a redistribution of $\mathrm{Zn}$, group-III species and holes across the structure by means of a mechanism that can be divided into five stages: 1) the injection of group-III interstitials during the growth of the n-type layer, 2) the diffusion of these defects from the surface to the buried Zn-doped layers, 3) the kick-out mechanism, which transfers $\mathrm{Zn}$ from a substitutional to an interstitial position, 4) the diffusion of interstitial $\mathrm{Zn}$ and, finally, 5) the Frenkel reaction, which pushes the $\mathrm{Zn}$ back to a group-III lattice site and releases new interstitial group-III atoms. On the other hand, the bandgap in a GaInP alloy highly depends on the spontaneous $\mathrm{CuPt}$ ordering produced by the arrangement in alternate (111) planes of the group-III sublattice atoms during the growth [9]. The $\mathrm{Zn}$ diffusion in an AlGaInP/GaInP system implies the transfer of group-III elements to interstitial positions -equation (1), from right to left-, with subsequent kick-out processes -equation (1), from left to right. As a consequence, the constant movement of group-III species throughout different positions of the crystal lattice favors the disruption of the metastable arrangement of $\mathrm{Ga}$ and $\mathrm{In}$ atoms present in ordered GaInP and thereby can modify the bandgap of the GaInP layer [10].

The incorporation of highly doped n-type layers in III-V structures is required in most optoelectronic applications. For example, in a MJSC the different bandgap subcells are monolithically integrated through optically transparent tunnel diodes, also termed tunnel junctions (TJ). A TJ is essentially a thin $p n$ junction that exhibits a low resistive behavior as long as the electrical conduction is assisted by the tunnel effect. These thin layers enable the interconnection of different subcells with negligible electrical losses. In order to obtain a high peak current and a

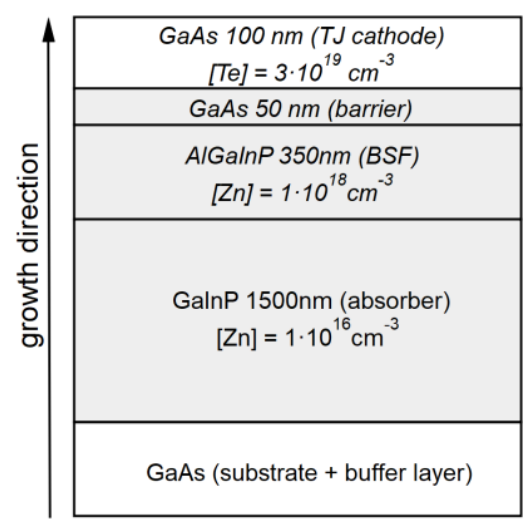

Fig. 1 Sketch of the baseline structure with the baseline doping levels used. The parameters varied in this structure are: (1) the doping density in the cathode of the TJ, (2) the cathode material used in the TJ, (3) the Al content in the BSF layer and, finally, (4) the material and thickness of the barrier layer. The GaInP absorber is identical in all cases. 


\section{Postprint version of paper: 10.1109/JPHOTOV.2020.3043849}

low resistivity, highly doped cathode and anode layers, with typical doping densities exceeding $1 \cdot 10^{19} \mathrm{~cm}^{-3}$, are required [11]. Hence, the integration of tunnel junctions in the semiconductor structure represents an unavoidable injection of point defects that can potentially interact with the electrically active $\mathrm{Zn}$ found in already grown surrounding layers. For instance, in inverted multijunction solar cells, the TJ's are grown immediately after the passivating back surface field (BSF) layers of the subcells, where concentrations of $\mathrm{Zn}$ around $1 \cdot 10^{18} \mathrm{~cm}^{-3}$ are typically found, turning out the diffusion of $\mathrm{Zn}$ almost unavoidable [12][13]. In this work, we investigate the dynamics of $\mathrm{Zn}$ diffusion in different $\mathrm{p}$-AlGaInP/p-GaInP systems corresponding to the TJ-cathode/barrier/BSF/absorber layers of a GaInP subcell integrated into a MJSC system. The baseline structure used in the study, represented in Fig. 1, mimics the layer arrangement in an inverted GaInP solar cell with a tunnel junction grown on top. In previous works we observed that the AlGaAs: $\mathrm{C}$ anode of the TJ does not play a significant role in the $\mathrm{Zn}$ diffusion mechanism. For simplicity and to prevent complications during the etching steps of the capacitance-voltage measurements (ECV) of the cathode layer, the anode is not included in the baseline structure. From this generic structure, we modify systematically structural and growth parameters to evaluate their impact on the $[\mathrm{Zn}]$ and $\left[\mathrm{h}^{+}\right]$profiles. In particular we focus on: 1) the influence of the doping level used in the cathode of the TJ; 2) the use of different TJ cathode materials, 3) the use of $(\mathrm{Al})(\mathrm{Ga}) \mathrm{InP}$ alloys with different $\mathrm{Al}$ content in the BSF and, finally, (4) the effectiveness of using different barrier layers to stop the propagation of point defects from the cathode to the BSF. The effect of $\mathrm{Zn}$ diffusion on the GaInP bandgap are further analyzed by using the cathodoluminescence (CL) technique.

\section{EXPERIMENTAL}

All samples were grown on GaAs substrates with a $2^{\circ}$ miscut towards the (111)B plane in a horizontal lowpressure MOVPE reactor (AIX200/4) at $100 \mathrm{mbar}$. The precursors used were $\mathrm{AsH}_{3}$ and $\mathrm{PH}_{3}$ for group-V, TMGa and TMIn for group-III and DETe and DMZn for dopant elements. The GaAs cathode layer was grown at $550^{\circ} \mathrm{C}$, with a deposition rate of $2.1 \mu \mathrm{m} / \mathrm{h}$ and the $\mathrm{V} / \mathrm{III}$ ratio was 20. The GaInP, AlGaInP and AlInP layers were grown at $675^{\circ} \mathrm{C}, 4 \mu \mathrm{m} / \mathrm{h}$ and with V/III ratios of 110,110 and 140 , respectively. The partial pressures of DMZn and DETe used to obtain p-type and n-type electrical doping are specified in Table I. The DMZn used in the absorber and the BSF layers was kept constant in all samples, intending to attain doping levels of $\sim 1 \cdot 10^{16} \mathrm{~cm}^{-3}$ and $\sim 1 \cdot 10^{18} \mathrm{~cm}^{-3}$, respectively. On the other hand, the barrier layers were nominally undoped. An ex-situ MOVPE thermal annealing process of 60 minutes at $675^{\circ} \mathrm{C}$ under $\mathrm{AsH}_{3}$ environment was conducted in all samples in order to reproduce the thermal load of a complete epitaxial process of a 2-junction solar cell. The results presented correspond to the annealed samples unless the contrary is specified. Solar cell devices were fabricated using the inverted metamorphic (IMM) solar cell fabrication process as described elsewhere [14] with an active area of $0.1 \mathrm{~cm}^{2}$. Both front and rear contacts are based on $\sim 300 \mathrm{~nm}$ of gold deposited by electroplating. All the layers are latticematched to GaAs, as confirmed by the high-resolution X-ray diffraction (HRXRD) measurements on the $\mathrm{Ga}_{0.5} \mathrm{In}_{0.5} \mathrm{P}$, $\mathrm{Al}_{0.2} \mathrm{Ga}_{0.3} \mathrm{In}_{0.5} \mathrm{P}$ and $\mathrm{Al}_{0.5} \mathrm{In}_{0.5} \mathrm{P}$ layers. The free-carrier and $\mathrm{Zn}$ concentrations depth profiles were measured by ECV and secondary ion mass spectroscopy (SIMS) techniques. In the SIMS profiles, all layers were delineated through the detection of $\mathrm{Al}$, In, $\mathrm{P}$ and As. The donor concentration in the cathode layer $\left(\mathrm{N}_{\mathrm{D}}\right)$ was obtained through the electron concentration (n) measured by ECV. The growth conditions favor the formation of a high CuPt ordering in the group-III sublattice of GaInP, which can be disrupted by the diffusion

TABLE I. GROWTH DETAILS OF THE SAMPLES

\begin{tabular}{|c|c|c|c|c|c|}
\hline ID & Cathode & $\begin{array}{c}\text { Pete cathode }_{\text {Dete }} \\
\text { (mbar })\end{array}$ & $\begin{array}{c}{\left[\mathrm{N}_{\mathrm{D}}\right] \text { cathode }} \\
\left(\mathrm{cm}^{-3}\right)\end{array}$ & Barrier & BSF \\
\hline A & GaAs & 0 & - & $50 \mathrm{~nm} \mathrm{GaAs}$ & AlGaInP \\
\hline B & GaAs & $2.05 \cdot 10^{-6}$ & $8 \cdot 10^{18}$ & $50 \mathrm{~nm} \mathrm{GaAs}$ & AlGaInP \\
\hline $\mathrm{C}$ & GaAs & $1.03 \cdot 10^{-5}$ & $1 \cdot 10^{19}$ & $50 \mathrm{~nm} \mathrm{GaAs}$ & AlGaInP \\
\hline $\mathrm{D}$ & GaAs & $2.05 \cdot 10^{-5}$ & $3 \cdot 10^{19}$ & $50 \mathrm{~nm} \mathrm{GaAs}$ & AlGaInP \\
\hline $\mathrm{E}$ & AlInP & 0 & - & $50 \mathrm{~nm} \mathrm{GaAs}$ & AlGaInP \\
\hline $\mathrm{F}$ & AlInP & $2.57 \cdot 10^{-5}$ & $5 \cdot 10^{18}$ & $50 \mathrm{~nm} \mathrm{GaAs}$ & AlGaInP \\
\hline G & GaAs & $2.05 \cdot 10^{-5}$ & $3 \cdot 10^{19}$ & $500 \mathrm{~nm} \mathrm{GaAs}$ & AlGaInP \\
\hline $\mathrm{H}$ & GaAs & $2.05 \cdot 10^{-5}$ & $3 \cdot 10^{19}$ & $50 \mathrm{~nm}$ AlAs & AlGaInP \\
\hline I & GaAs & $2.05 \cdot 10^{-5}$ & $3 \cdot 10^{19}$ & $50 \mathrm{~nm}$ AlInP & AlGaInP \\
\hline $\mathrm{J}$ & GaAs & $2.05 \cdot 10^{-5}$ & $3 \cdot 10^{19}$ & $50 \mathrm{~nm} \mathrm{GaAs}$ & GaInP \\
\hline $\mathrm{K}$ & GaAs & $2.05 \cdot 10^{-5}$ & $3 \cdot 10^{19}$ & $50 \mathrm{~nm} \mathrm{GaAs}$ & AlInP \\
\hline
\end{tabular}

*The thickness of the cathode, BSF and absorber layers are $100 \mathrm{~nm}, 350 \mathrm{~nm}$ and $1500 \mathrm{~nm}$.

**The DMZn partial pressure used during the growth of the BSF and absorber layers was identical in all samples: $\mathrm{P}_{\mathrm{DMZn}}=1.02 \cdot 10^{-2} \mathrm{mbar}$ in the BSF and $\mathrm{P}_{\mathrm{DMZn}}=2.8 \cdot 10^{-5}$ mbar in the absorber. 


\section{Postprint version of paper: 10.1109/JPHOTOV.2020.3043849}

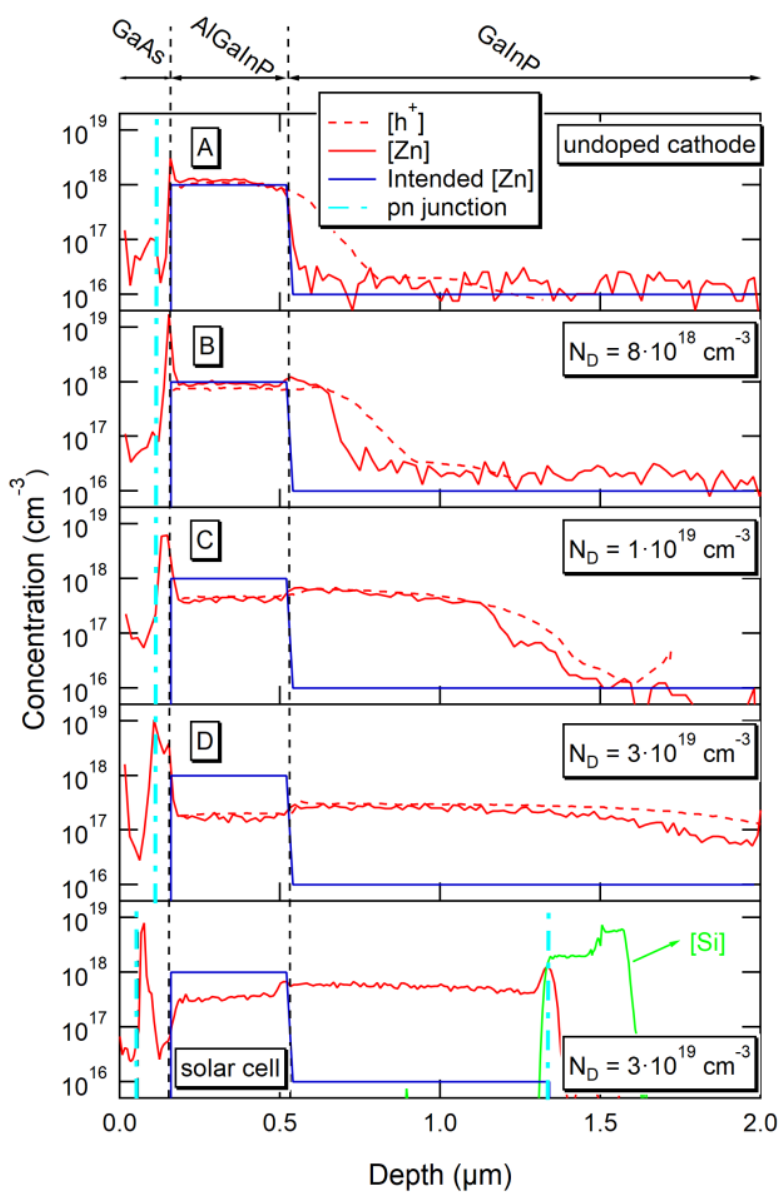

Fig. 2. Depth profiles of $[\mathrm{Zn}]$ and $\left[\mathrm{h}^{+}\right]$in the AlGaInP/GaInP layers of samples A, B, C, D -with increasing donor concentration in the GaAs cathode layer- and a reference solar cell incorporating a TJ with the same cathode as D. The position of pn junctions in each structure is also indicated.

of $\mathrm{Zn}$. This was analyzed by spectrally resolved plan view luminescence scans from the AlGaInP/GaInP (BSF/absorber) structures, collected at $83 \mathrm{~K}$ by the cathodoluminescence (CL) technique using a monoCL 2 (Gatan UK) CL system attached to a LEO 1530 (Carl-Zeiss) field-emission scanning electron microscope (FESEM), using e-beams of $5 \mathrm{kV}$. The details of the samples are summarized in Table I. Finally, I-V curves under concentration were measured in the solar cells using a custom made, flash-lamp based, setup.

\section{RESULTS}

\section{A. Effect of the cathode doping level on Zn diffusion}

First, we focus on the influence of the n-type doping level in the GaAs cathode on the diffusion of $\mathrm{Zn}$ along an AlGaInP/GaInP system. For this, we use samples A, B, C and $\mathrm{D}$, with identical structures and growth conditions, but different $[\mathrm{Te}]$ in the cathode. $[\mathrm{Zn}]$ and $\left[\mathrm{h}^{+}\right]$depth profiles are shown in Fig. 2. In general, the ECV profiles match the SIMS profiles, but some differences are found in the transition regions. This is due to the spatial resolution of the ECV measurement, which integrates the depletion region width at each point. Thus, the spatial resolution fluctuates between 20 and $200 \mathrm{~nm}$ depending on the concentration level. The doping attained in the AlGaInP and GaInP layers matches the desired profile in the absence of a doped

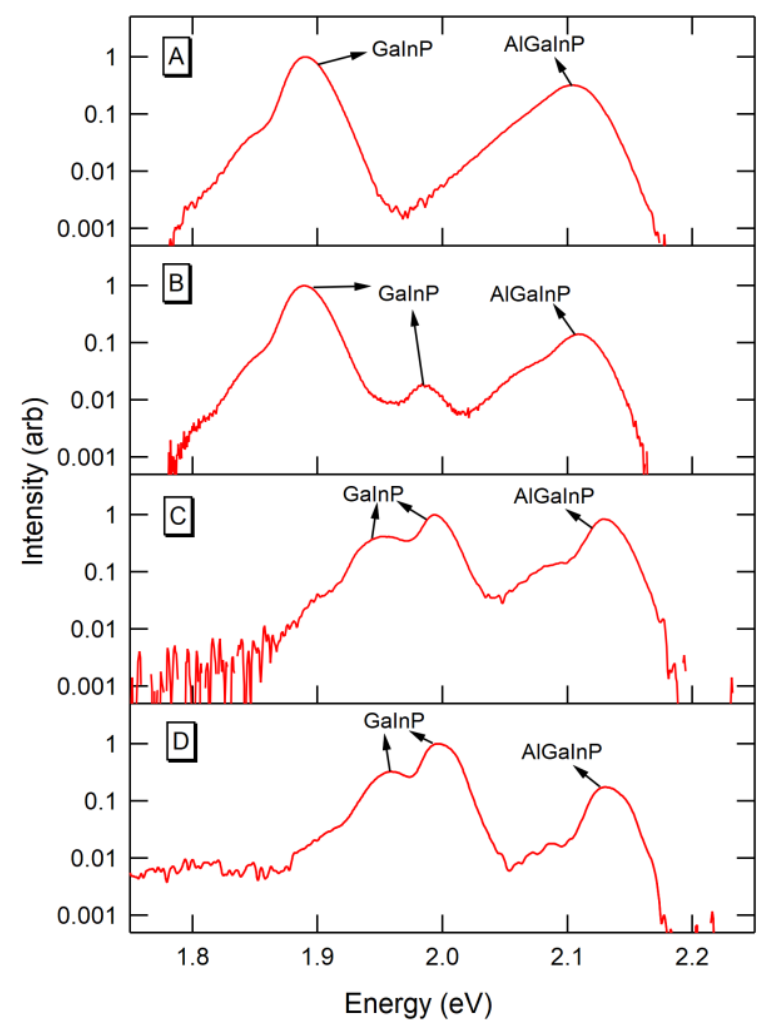

Fig.3. CL spectral emission of samples A, B, C and D. The peaks in CL are labeled identifying the layer where the emission is originated: the absorber GaInP and the BSF AlGaInP.

cathode (A). In contrast, the $[\mathrm{Zn}]$ and $\left[\mathrm{h}^{+}\right]$profiles become dramatically altered as the GaAs layer is increasingly doped (B, C and D). As a result of the diffusion process, the $\left[\mathrm{h}^{+}\right]$ profile flattens. The position of the diffusion front inside the GaInP absorber, together with the drop of the [Zn] level from the nominal in the AlGaInP BSF, reflects the intensity of the process and shows the correlation with the donor concentration in the cathode layer. For instance, in the most severe diffusion case $\left(\mathrm{D}\right.$, with $\mathrm{N}_{\mathrm{D}}=3 \cdot 10^{19} \mathrm{~cm}^{-3}$ ), [Zn] has already spread all around the whole absorber GaInP layer and the level in the BSF layer has gone down from $1 \cdot 10^{18} \mathrm{~cm}^{-3}$ to $2 \cdot 10^{17} \mathrm{~cm}^{-3}$. The altered profiles reveal that the growth of a highly doped n-type GaAs layer after the $\mathrm{BSF}$, together with the presence of a concentration gradient and certain thermal energy, promotes the diffusion of $\mathrm{Zn}$. Otherwise, the diffusion of $\mathrm{Zn}$ is insignificant. This dynamic differs from a conventional diffusion process and suggests 1) the assistance of point defects injected during the growth of the TJ cathode, at an intensity related to the doping level, which activates the diffusion mechanism, and 2) different diffusivities of $\mathrm{Zn}$ depending on its position in the crystal lattice (substitutional or interstitial). According to the kickout reaction, the injected defects that reach the BSF layer transfer the electrically active $\mathrm{Zn}$ from a substitutional acceptor position -group-III sublattice- to a mobile interstitial position (equation (1), from left to right). As long as the density of the injected interstitial $\mathrm{Ga}$ depends on the electron concentration in the cathode, it becomes a key parameter to determine the intensity of the process: a higher $\mathrm{N}_{\mathrm{D}}$ in the cathode certainly induces a stronger and faster diffusion of $\mathrm{Zn}$. 


\section{Postprint version of paper: 10.1109/JPHOTOV.2020.3043849}

The accumulation of $\mathrm{Zn}$ that appears in the GaAs layer, close to the GaAs/p-AlGaInP interface coincides with the np junction formed by the n-type cathode layer. This indicates that the propagation of $\mathrm{Zn}$ is stopped by the built-in electric field of this $p n$ junction. In order to provide further insight on this point, the $[\mathrm{Zn}]$ profile of an inverted GaInP solar cell integrated into a MJSC is included in Fig. 2. The dopant flows used in the cathode of TJ and the BSF layers correspond to case $\mathrm{D}$, but the GaInP absorber layer comprises a $750 \mathrm{~nm} \mathrm{Zn}$-doped and a $180 \mathrm{~nm}$ Si-doped layers that form a deep $p n$ junction in the absorber layer. It can be seen that the Zn-redistribution is similar as in case A (demonstrating that the TJ anode plays no significant role), but the $\mathrm{Zn}$ coming from the BSF is stopped at the Si-doped emitter region. Note that the junction at the $\mathrm{TJ}$ is a bit shifted to the left in this case because of the presence of the anode layer. The donor concentration in the n-side close to the GaAs/AlGaInP interface $\left(\mathrm{N}_{\mathrm{D}}=3 \cdot 10^{19} \mathrm{~cm}^{-3}\right)$ is much higher than in the absorber junction $\left(\mathrm{N}_{\mathrm{D}}=1 \cdot 10^{18} \mathrm{~cm}^{-3}\right)$, so the magnitude of the electric field and the ability to stop charged species differs significantly. The difference in the level of [Zn] detected at both interfaces suggests an interaction between the internal electric fields and the mobile $\mathrm{Zn}$ : apparently, the higher the electric field, the higher the $\mathrm{Zn}$ peak concentration. In addition, the direction of the electric fields, from the n-layer to the p-layer, reveals
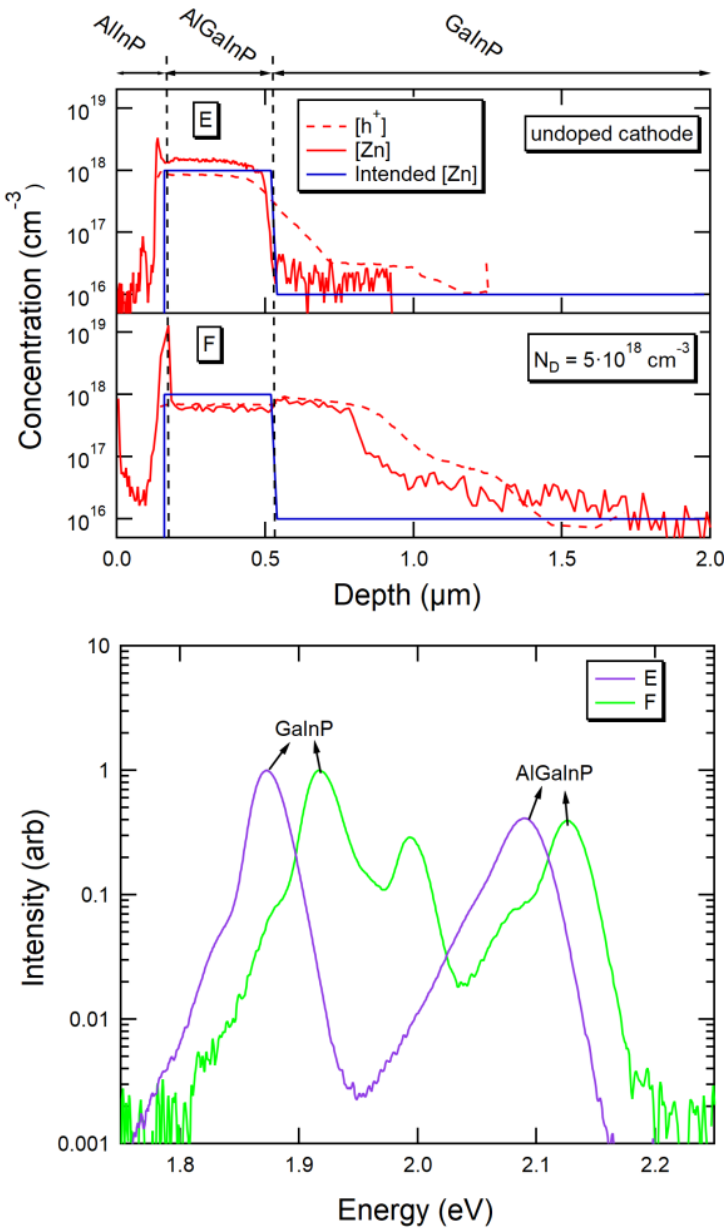

Fig. 4. Top: Depth profiles of $[\mathrm{Zn}]$ and $[\mathrm{h}+]$ in the AlGaInP/GaInP layers of Samples E and F -with doped and undoped AlInP cathode layers, respectively. Bottom: CL spectral emissions. that the mobile $\mathrm{Zn}$ is positively charged and, hence, occupies interstitial positions during the propagation. Similar accumulation of $\mathrm{Zn}$ at $p n$ junctions have been observed elsewhere [5][6][15].

The plan view CL spectral emissions at $83 \mathrm{~K}$ shown in Fig.3, are used to evaluate the impact of $\mathrm{Zn}$ diffusion on the bandgap of the GaInP absorber layer. HRXRD scans confirmed that the composition of GaInP layers was virtually identical, so the bandgap differences can be directly related to modifications in the ordering state. In the absence of $\mathrm{Zn}$ diffusion (case $\mathrm{A}$ ), the peak emission corresponding to the GaInP layer is produced at $1.89 \mathrm{eV}$. On the other hand, as the cathode is increasingly doped, the bandgap varies significantly. In $B\left(N_{D}=8 \cdot 10^{18} \mathrm{~cm}^{-3}\right)$, the GaInP CL emission is composed of two peaks: a primary peak, located at a similar energy as in A (1.89 eV), and a second peak, located at a higher energy $(1.99 \mathrm{eV})$. This value corresponds to the bandgap of the almost completely disordered GaInP at the CL measurement temperature [9]. In $\mathrm{C}$ and $\mathrm{D}$, with a more drastic $\mathrm{Zn}$ diffusion $\left(\mathrm{N}_{\mathrm{D}}>1 \cdot 10^{19} \mathrm{~cm}^{-3}\right)$, the main peak is located at $2 \mathrm{eV}$, with some low intense signal still detected at lower energies and a clear secondary peak at $1.95 \mathrm{eV}$. The absolute increase of the peak energy $(110 \mathrm{meV})$ reveals a drastic reduction of the average $\mathrm{CuPt}$ ordering degree related to the intensity of the
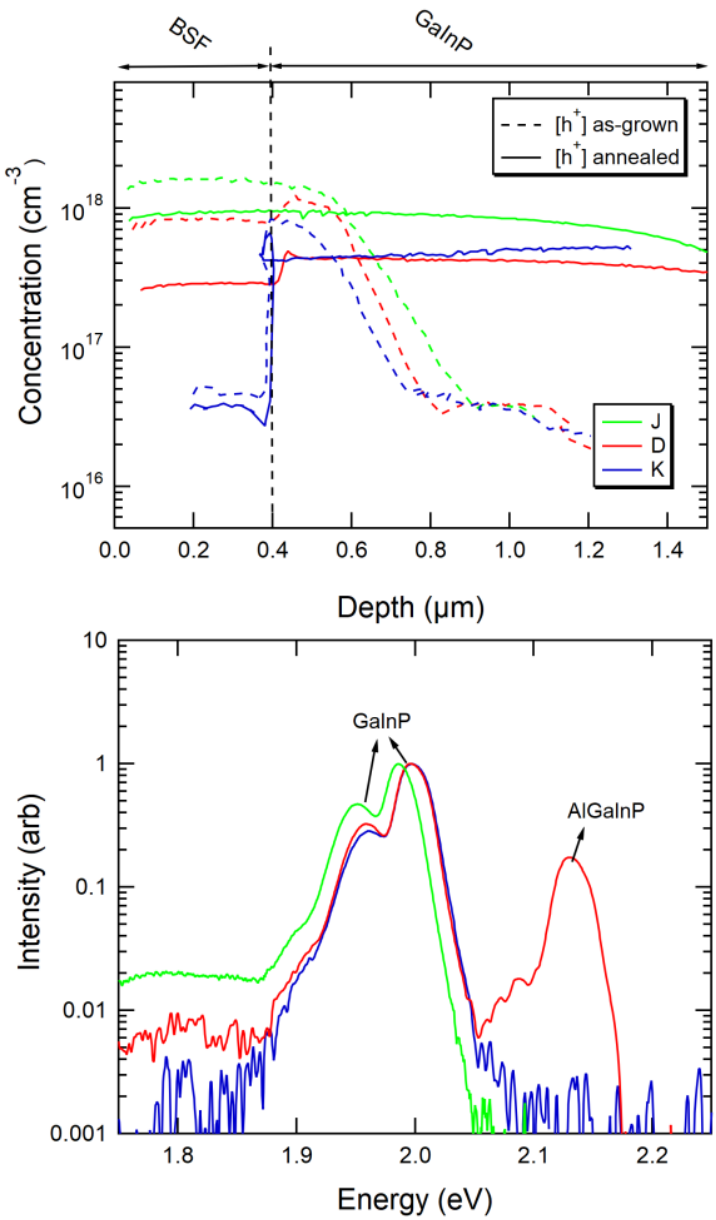

Fig. 5. Top: Depth profiles of $\left[\mathrm{h}^{+}\right]$in the AlGaInP/GaInP layers of as-grown and annealed Samples J, D and K -with BSF layers of GaInP, AlGaInP and AlInP, respectively. Bottom: CL spectral emissions of the annealed samples. 


\section{Postprint version of paper: 10.1109/JPHOTOV.2020.3043849}

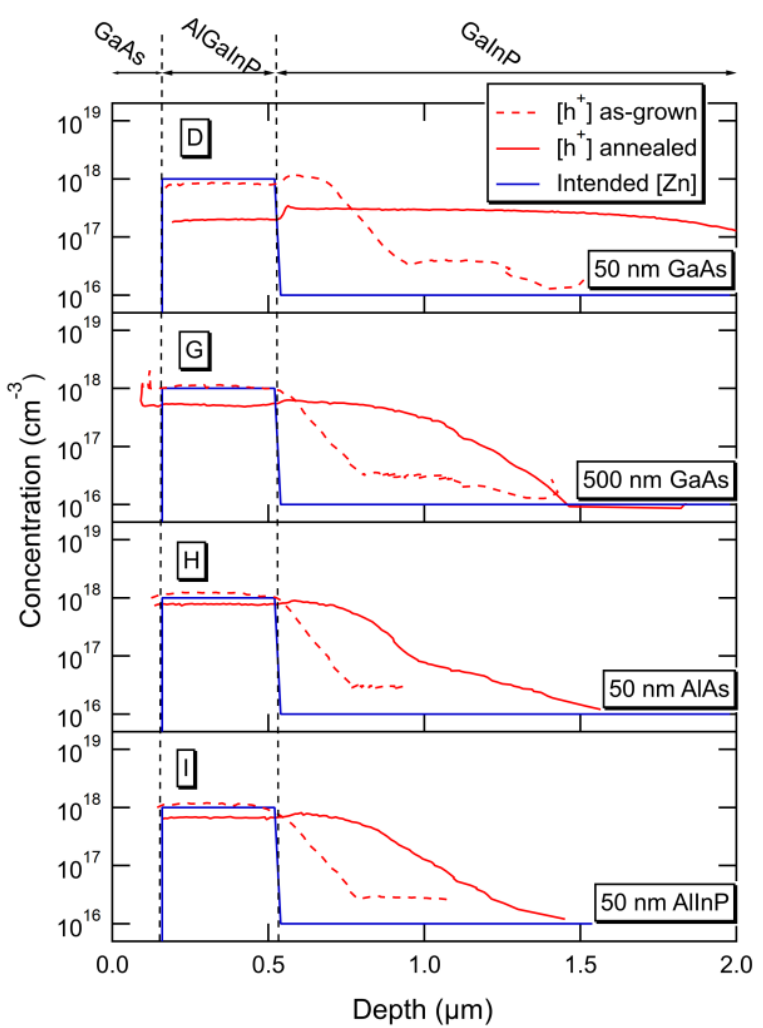

Fig. 6. Depth profiles of $[\mathrm{h}+]$ in the AlGaInP/GaInP layers of the as-grown and annealed Samples D, G, H and I, with varying barrier layers. The barriers are $50 \mathrm{~nm}$ GaAs (D), $500 \mathrm{~nm}$ GaAs (G), $50 \mathrm{~nm}$ AlAs $(\mathrm{H})$ and $50 \mathrm{~nm}$ AlInP (I), as indicated with the labels.

diffusion process. The bandgap variations induced by $\mathrm{Zn}$ diffusion affect the external quantum efficiency in the resulting GaInP solar cells, as shown in previous studies [12]. The emission of multiple peaks suggests the presence of regions with different ordering state in the GaInP absorber layer. In addition, the AlGaInP layers in samples $\mathrm{C}$ and $\mathrm{D}$ emit at $\sim 20 \mathrm{meV}$ higher energies than in $\mathrm{A}$, which suggest differences on the ordering state in those layers too.

\section{B. Effect of the cathode material on the injection of point defects and $\mathrm{Zn}$ diffusion}

Next, we focus on the influence of the material used as cathode in the TJ. Using alternative materials in this cathode might produce differences in the diffusion dynamics by modifying either the density or the nature of the injected point defects. Two structures using either an undoped (sample E) or a doped AlInP cathode (sample F) are evaluated, to test if group-III Al and In species can induce diffusion of $\mathrm{Zn}$ similarly as $\mathrm{Ga}$. The concentration profiles and the CL spectra are shown in Fig. 4. Again, the same trends are reproduced: the doping in the cathode activates the diffusion of $\mathrm{Zn}$ along the $\mathrm{AlGaInP}$ and GaInP layers as in Fig. 3. Therefore, the mechanism described by Deppe applies for different III-V systems: the kick-out and Frenkel reactions in (1) can be extended to other III-V materials by changing the $\mathrm{Ga}$ species by the corresponding group-III element. In this case, interstitial $\mathrm{Al}$ and/or interstitial In species may be injected during the growth of the n-AlInP layer. Note that although the $\mathrm{N}_{\mathrm{D}}$ in the AlInP cathode layer in $\mathrm{F}$ is lower than in the GaAs cathode in $\mathrm{B}$, the diffusion is stronger in the former (Fig. 2). This appears to be connected

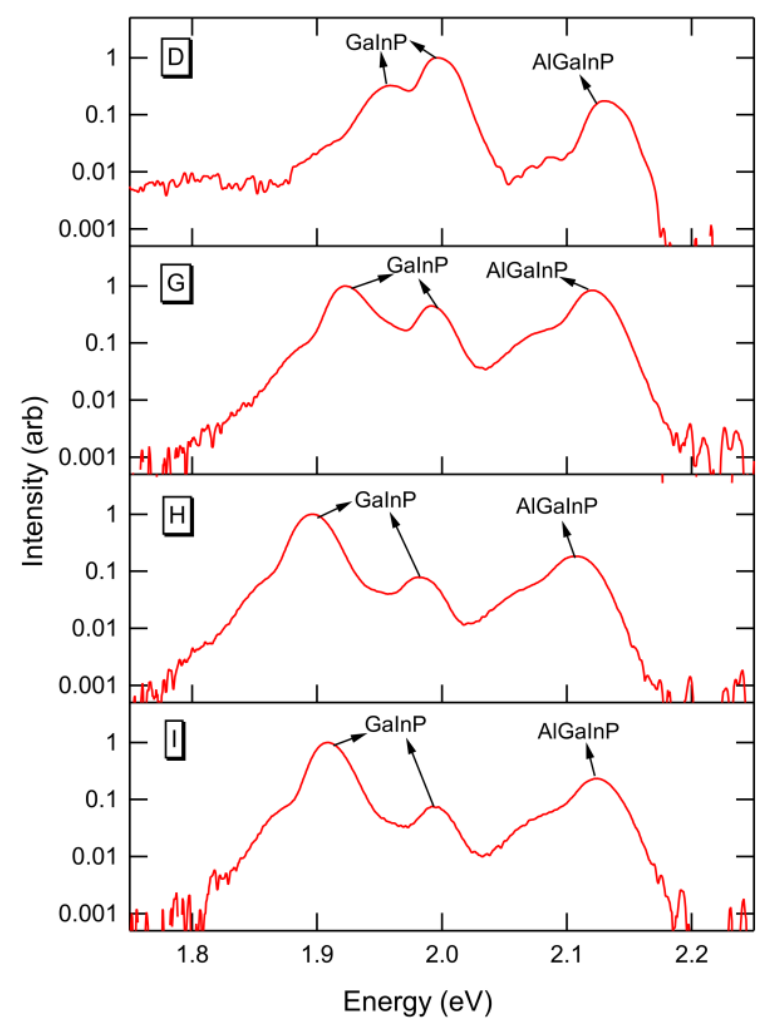

Fig. 7. CL spectral emission of annealed Samples D, G, H and I, with varying barrier layers. The barriers are $50 \mathrm{~nm}$ GaAs (D), $500 \mathrm{~nm}$ GaAs (G), $50 \mathrm{~nm} \mathrm{AlAs} \mathrm{(H)} \mathrm{and} 50 \mathrm{~nm}$ AlInP (I)

to the higher density of states in the conduction band of AlInP, as compared to GaAs [16], which produces a sharper gradient in the distance of Fermi level to conduction band between the surface and the bulk, and therefore a more intense imbalance and injection in group-III interstitials. The different nature of these point defects injected (Ga vs $\mathrm{Al}$ ) could also play a role. Finally, as expected from previous observations, the diffusion mechanism partially breaks the ordered arrangement of group-III species resulting in regions with different ordering and multiple peaks in the CL emission (Fig.4, bottom).

\section{Influence of the BSF material on the diffusion process}

In the following, we assess the diffusion dynamics in $\mathrm{Zn}$ doped BSF (Al)(Ga)InP alloys with different $\mathrm{Al}$ content susceptible to be used as BSF layers in a GaInP solar cell. In particular, BSFs of GaInP, AlGaInP and AlInP are evaluated in samples $\mathrm{J}, \mathrm{D}$ and $\mathrm{K}$, respectively. It must be considered that, although the amount of $\mathrm{Zn}$ injected during the growth of the BSF was kept constant in all the cases, the [Zn] level attained in these layers before diffusion differs from one sample to the other due to differences on the incorporation of $\mathrm{Zn}$. Calibration samples grown without doped layers on top were used to measure the $\mathrm{Zn}$ level attained in the BSF in the absence of diffusion. The levels of $[\mathrm{Zn}]$ and $\left[\mathrm{h}^{+}\right]$ detected by SIMS and ECV were: $2 \cdot 10^{18} \mathrm{~cm}^{-3}, 1 \cdot 10^{18} \mathrm{~cm}^{-3}$ and $3 \cdot 10^{17} \mathrm{~cm}^{-3}$ in GaInP, AlGaInP and AlInP layers. This points out important differences on the incorporation rate of $\mathrm{Zn}$ as the $\mathrm{Al}$ content in the alloy is raised. Anyway, [Zn] level in the GaInP absorber layer should be around $10^{16} \mathrm{~cm}^{-3}$ in all cases, and any variation around this value can be used to detect diffusion from the BSF layer. The contrast between 


\section{Postprint version of paper: 10.1109/JPHOTOV.2020.3043849}

the profiles of $\left[\mathrm{h}^{+}\right]$before and after the annealing process, shown in Fig. 5, top, reveals a strong diffusion in all samples. Note that in this case, the assessment is somehow affected by a significantly different profile between asgrown samples. In the as-grown samples, the point defects have already been injected in the structure and, therefore, the diffusion has already started during the cooling down. Consequently, the $\mathrm{Zn}$ element can occupy both interstitial (non-electrically active) and substitutional (active) position in the crystal lattice. This implies that the total quantity of free holes does not have to be necessarily constant during the different stages of the annealing process. This becomes particularly clear in case $\mathrm{K}$, which exhibits a large difference between the doping obtained in calibration samples without diffusion, and the doping measured in the as-grown structure shown in Figure 5. Besides, the lower level of $\left[\mathrm{h}^{+}\right]$detected in the annealed BSF layers as the content of $\mathrm{Al}$ increases, is consistent with a decrease in the solubility of $\mathrm{Zn}$ in $\mathrm{AlGaInP}$ alloys as the fraction of $\mathrm{Al}$ increases [17], in a similar way as the incorporation rate measured from calibration samples. This fact influences on the equilibrium $[\mathrm{Zn}]$ profile in the layers of the structure. In addition to a different doping level in the BSF layer, a discontinuity in $\left[\mathrm{h}^{+}\right]$is observed at the BSF/GaInP interface for those BSF layers containing Al. Finally, as expected, the bandgap of the GaInP absorber layers reflects that the group-III ordering in GaInP has been almost completely disrupted in all cases (Fig.5, bottom).

\section{Incorporating barrier layers to reduce diffusion}

We have shown that the Zn-redistribution takes place independently of the materials used in either the cathode or the BSF, complicating the integration of the GaInP subcell in MJSC structures. A reduction of the donor concentration in the cathode might mitigate the diffusion (as shown in Fig. 2) but would take a toll on the electric performance of the $\mathrm{TJ}$, as the tunnel effect is intimately related to the doping level of the anode and the cathode of the TJ. On the other hand, the structure of a TJ typically includes two cladding layers, also termed barrier layers, designed to minimize the out-diffusion of electrically active dopant elements from the TJ to the rest of the structure [18] [19]. The MJSC structure design can take advantage of these layers to additionally hinder the out-diffusion of the injected interstitial point defects and thus reduce the $\mathrm{Zn}$ diffusion produced in surrounding layers.

This way, we study the effectiveness of a set of barriers, placed between the cathode and the BSF layer, with the purpose of trapping the point defects injected from the TJ cathode, (see Fig.1). The barrier layers tested consist of a 50 $\mathrm{nm}$ GaAs layer (D), a $500 \mathrm{~nm} \mathrm{GaAs} \mathrm{layer} \mathrm{(G),} \mathrm{a} 50 \mathrm{~nm}$ AlAs layer $(\mathrm{H})$ and a $50 \mathrm{~nm}$ AlInP layer (I). The rest of the structure is kept unchanged in all samples (see Table I). The ECV profiles, presented in Fig. 6, show that a considerable reduction of the $\mathrm{Zn}$ diffusion can be achieved by increasing the thickness of the GaAs barrier from 50 to $500 \mathrm{~nm}$ (case D vs case $\mathrm{G}$ ). The Al-based barriers like AlAs or AlInP prove to further reduce the diffusion, even for one order of magnitude less thickness. This fact may be explained by differences in the solubility and/or diffusivity of the interstitial $\mathrm{Ga}$ defects in the material of the barrier, or as the Al fraction varies [20]. Accordingly, the reduction of $\mathrm{Zn}$ diffusion implies a higher overall ordering degree in the GaInP layer: the ordered GaInP dominates the CL emission in $\mathrm{G}$ and, more importantly, in $\mathrm{H}$ and I (Fig. 7). These results demonstrate that thick $\mathrm{n}-\mathrm{Al}(\mathrm{Ga}) \mathrm{As}$ layers could be effective to minimize the diffusion of $\mathrm{Zn}$ thanks to a decrease of the injection of point defects from the TJ cathode, thus enabling the integration of a highly doped TJ in a MJSC device.

\section{E. Impact of Zn diffusion on the perfomance of the solar cell}

The diffusion of $\mathrm{Zn}$ may bring about substantial changes in the optoelectronic performance of a solar cell. First, the increase of the bandgap in GaInP reduces the cut-off wavelength in the QE and lowers the photogenerated current of the subcell [12]. On the other hand, the increase of the bandgap can be used to increase the open-circuit-voltage $\left(\mathrm{V}_{\mathrm{oc}}\right)$, if the material quality is maintained. Since the ideal bandgap for the top subcell in MJSC's with 2, 3 and 4 junctions is higher than the obtained in ordered-GaInP [21],
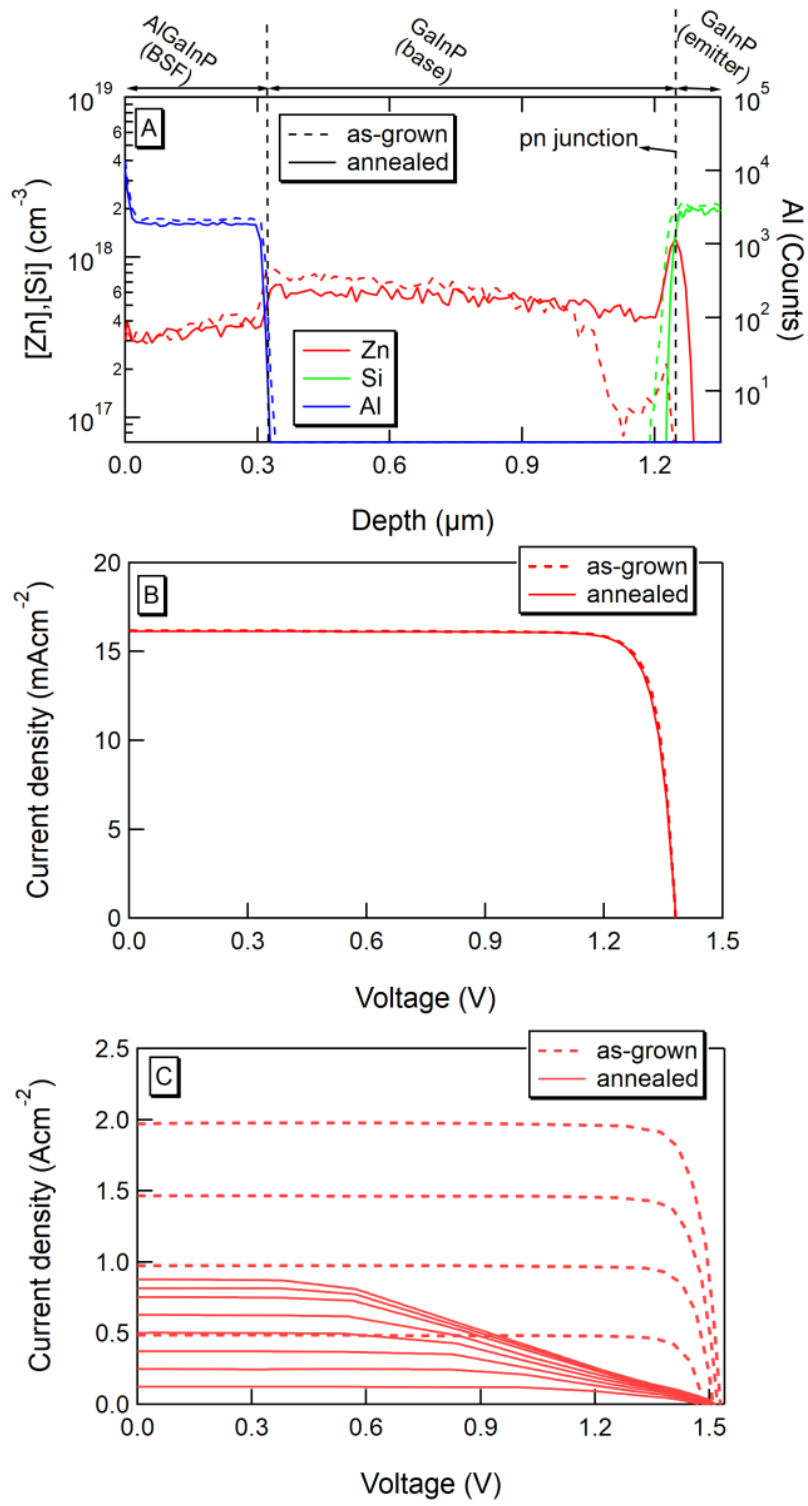

Fig. 8. For as-grown and annealed solar cells: SIMS profile of $\mathrm{Zn}$, $\mathrm{Si}$ and $\mathrm{Al}(\mathrm{A})$; I-V curves at an irradiance around 1 sun (B); and I-V curves under concentration $(\mathrm{C})$. 


\section{Postprint version of paper: 10.1109/JPHOTOV.2020.3043849}

the disordering caused by a controlled $\mathrm{Zn}$ diffusion might be potentially beneficial. In contrast, the deviations in the electrical doping from the nominal values can take a toll on the electrical performance of the solar cell as well. For instance, the redistribution of $\mathrm{Zn}$ has already demonstrated to produce multiple detrimental effects on the solar cell such as the introduction electrical barriers located at the BSF/absorber interfaces [5] or the deterioration of the backsurface-passivation [22].

To evaluate the impact of $\mathrm{Zn}$ diffusion on a real solar cell device we compare two identical inverted GaInP solar cells (as-grown and annealed) that incorporate a complete TJ. The only difference between both samples is that the $\mathrm{Zn}$ profile in the annealed solar cell is varied through an ex-situ MOVPE annealing of 60 minutes at $675^{\circ} \mathrm{C}$. The growth conditions reproduce those used in the case $\mathrm{A}$, aiming to promote a strong $\mathrm{Zn}$ diffusion across the structure. The SIMS profiles of $[\mathrm{Zn}],[\mathrm{Si}]$ and $[\mathrm{Al}]$ are presented in Fig. 8, A.

A strong Zn diffusion can be appreciated in both cases, which is consistent with the results presented in the preceding sections. Nonetheless, a relevant difference is observed: the diffusion front in the as-grown solar cell is still comprised within the base layer, whereas in the annealed solar cell the diffusing $\mathrm{Zn}$ has already extended all over the base up to the $p n$ junction. Hence, the incoming $\mathrm{Zn}$ is expected to partially counterbalance the effective n-type doping of the emitter. Consistently, the emitter sheet resistance $\left(R_{\text {she }}\right)$ measured in the annealed case $(1800 \Omega / s q)$ is significantly higher than the obtained in the as-grown sample $(450 \Omega / \mathrm{sq})$. Since the lateral spreading of the current flow from the absorber layers towards the front metal contact occurs mainly in the emitter layer, the overall series resistance of the solar cell is intimately related to the $R_{\text {she }}$. Although the I-V curves at $\sim 1$ sun are almost identical (Fig.8, B), the impact of the series resistance becomes clear at higher irradiances (Fig.8, C). In the annealed case, the fill factor (FF) decays at very low concentrations, whereas the FF does not decay until higher $J_{\text {sc }}$ than $2.5 \mathrm{Acm}^{-2}$ in the as-grown sample. At this current level, the front-contact metallization may be dominating the series resistance of the device.

Therefore, in these solar cells, no noticeable internal resistive barrier is produced at the $\mathrm{BSF} /$ base interface, but $\mathrm{Zn}$ diffusion on the front layers of the structure can spoil the conductivity of the device. Although the conductivity in the emitter could be increased by modifying the thickness and/or the n-type doping of this layer, it would be desirable to prevent $\mathrm{Zn}$ from reaching the emitter in order to avoid additional modifications in the solar cell design. The barrier layers studied in previous sections would help attaining this.

\section{CONCLUSIONS}

The $\mathrm{Zn}$ diffusion dynamics in different AlGaInP/GaInP material systems corresponding to a GaInP subcell integrated into an inverted MJSC has been extensively evaluated from the perspective of the model proposed by Deppe et. al, which contemplates the assistance of point defects in the process. In particular, we have demonstrated that the growth of the cathode of the TJ after the GaInP subcell leads to an injection of point defects that induce an enhanced diffusion of $\mathrm{Zn}$ from the BSF to the rest of the structure. In particular, the injected group-III interstitials transfer the electrically active $\mathrm{Zn}$ from a substitutional to an interstitial position where the diffusivity is much higher. The injected concentration of group-III interstitial atoms depends on the electron concentration used in the cathode layer so the doping level in this layer is key to determine the intensity of the diffusion process regardless of the material used in the $\mathrm{TJ}$ or the $\mathrm{Al}$ content in the BSF. These results can be extrapolated to any $(\mathrm{Al})(\mathrm{Ga}) \mathrm{InP} / \mathrm{GaInP}$ system including highly doped n-type layers in the structure. We demonstrate that the diffusion of point defects can be mitigated by including $\mathrm{Al}(\mathrm{Ga}) \mathrm{As}$ or $\mathrm{AlInP}$ barrier layers with the proper thickness between the cathode and the BSF, which would enable the integration of highly $\mathrm{Zn}$-doped BSF layers into a MJSC structure. Finally, by comparing exemplary solar cells devices with different $\mathrm{Zn}$-profiles, we show that $\mathrm{Zn}$ diffusion can deteriorate the conductivity of the device when it reaches the emitter layer. On the other hand, no evidence of electrical barriers in the BSF/base interface were observed. These observations can help to define what could be considered a controlled $\mathrm{Zn}$ diffusion in the GaInP top subcell of an inverted MJSC.

\section{ACKNOWLEDGMENT}

This project has been funded by the Spanish MINECO with the project TEC2017-83447-P, by the Comunidad de Madrid with the project with reference Y2018/EMT-4892 (TEFLON-CM) and by Universidad Politécnica de Madrid by Programa Propio. M. Hinojosa is funded by the Spanish MECD through a FPU grant (FPU-15/03436) and I. García is funded by the Spanish Programa Estatal de Promoción del Talento y su Empleabilidad through a Ramon y Cajal grant (RYC-2014- 15621). S. Dadgostar was funded by JCYL and FEDER (Project VA283P18).

\section{REFERENCES}

[1] K. Kurishima, T. Kobayashi, H. Ito, i U. Gösele, «Control of Zn diffusion in InP/InGaAs heterojunction bipolar transistor structures grown by metalorganic vapor phase epitaxy», Journal of Applied Physics, vol. 79, núm. 8, p. 4017-4023, abr. 1996, doi: 10.1063/1.361830.

[2] Y. C. Shin, B. J. Kim, D. H. Kang, Y. M. Kim, i T. G. Kim, «Investigation of $\mathrm{Zn}$ diffusion by SIMS and its effects on the performance of AlGaInP-based red lasers», Semicond. Sci. Technol., vol. 21, núm. 1, p. 35-39, nov. 2005, doi: 10.1088/02681242/21/1/006.

[3] W. S. Hobson, S. J. Pearton, i A. S. Jordan, «Redistribution of Zn in GaAs-AlGaAs heterojunction bipolar transistor structures», Appl. Phys. Lett., vol. 56, núm. 13, p. 1251-1253, març 1990, doi: 10.1063/1.102528.

[4] N. Nordell, P. Ojala, W. H. van Berlo, G. Landgren, i M. K. Linnarsson, «Diffusion of $\mathrm{Zn}$ and $\mathrm{Mg}$ in $\mathrm{AlGaAs} / \mathrm{GaAs}$ structures grown by metalorganic vapor-phase epitaxy», Journal of Applied Physics, vol. 67, núm. 2, p. 778-786, gen. 1990, doi: 10.1063/1.345731.

[5] K. L. Schulte, M. A. Steiner, M. R. Young, i J. F. Geisz, «Internal Resistive Barriers Related to Zinc Diffusion During the Growth of Inverted Metamorphic Multijunction Solar Cells», IEEE Journal of Photovoltaics, vol. 9, núm. 1, p. 167-173, gen. 2019, doi: 10.1109/JPHOTOV.2018.2878317.

[6] C. Y. Chen, R. M. Cohen, D. S. Simons, i P. H. Chi, «Enhanced Zn diffusion in GaAs pnpn structures: Growth versus annealing», Appl. Phys. Lett., vol. 67, núm. 10, p. 1402-1404, set. 1995, doi: 10.1063/1.114507.

[7] P. M. Enquist, «Secondary ion mass spectroscopy depth profiles of heterojunction bipolar transistor emitter-base heterojunctions grown 


\section{Postprint version of paper: 10.1109/JPHOTOV.2020.3043849}

by low pressure OMVPE», Journal of Crystal Growth, vol. 93, núm. 1, p. 637-645, gen. 1988, doi: 10.1016/0022-0248(88)905969.

[8] D. G. Deppe, «Thermodynamic explanation to the enhanced diffusion of base dopant in AlGaAs-GaAs npn bipolar transistors», Appl. Phys. Lett., vol. 56, núm. 4, p. 370-372, gen. 1990, doi: 10.1063/1.102788.

[9] M. C. DeLong et al., «Band gap of "completely disordered" Ga0.52In0.48P», Appl. Phys. Lett., vol. 66, núm. 23, p. 3185-3187, juny 1995, doi: 10.1063/1.113717.

[10] P. Gavrilovic et al., «Disordering of the ordered structure in MOCVD-grown GaInP and AlGaInP by impurity diffusion and thermal annealing», Journal of Crystal Growth, vol. 93, núm. 1, p. 426-433, gen. 1988, doi: 10.1016/0022-0248(88)90563-5.

[11] I. García, I. Rey-Stolle, i C. Algora, «Performance analysis of AlGaAs/GaAs tunnel junctions for ultra-high concentration photovoltaics», J. Phys. D: Appl. Phys., vol. 45, núm. 4, p. 045101, gen. 2012, doi: 10.1088/0022-3727/45/4/045101.

[12] M. Hinojosa, I. García, I. Rey-Stolle, i C. Algora, «Evidence of enhanced $\mathrm{Zn}$-diffusion observed during the growth of Inverted Metamorphic Solar Cells», en 2019 IEEE 46th Photovoltaic Specialists Conference (PVSC), juny 2019, p. 0049-0053, doi: 10.1109/PVSC40753.2019.8980468.

[13] J. F. Geisz et al., «Six-junction III-V solar cells with $47.1 \%$ conversion efficiency under 143 Suns concentration», Nature Energy, vol. 5, núm. 4, Art. núm. 4, abr. 2020, doi: 10.1038/s41560-020-0598-5.

[14] J. F. Geisz et al., «High-efficiency GaInP/GaAs/nGaAs triplejunction solar cells grown inverted with a metamorphic bottom junction», Applied Physics Letters, vol. 91, núm. 2, p. 023502, 2007, doi: 10.1063/1.2753729.

[15] C. Blaauw, F. R. Shepherd, i D. Eger, «Secondary ion mass spectrometry and electrical characterization of $\mathrm{Zn}$ diffusion in n-type InP», Journal of Applied Physics, vol. 66, núm. 2, p. 605 610, jul. 1989, doi: 10.1063/1.343525.

[16] S. Adachi, Properties of Semiconductor Alloys: Group-IV, III-V and II-VI Semiconductors. John Wiley \& Sons, 2009.

[17] Y. Ohba, Y. Nishikawa, C. Nozaki, H. Sugawara, i T. Nakanisi, «A study of p-type doping for AlGaInP grown by low-pressure MOCVD», Journal of Crystal Growth, vol. 93, núm. 1, p. 613-617, gen. 1988, doi: 10.1016/0022-0248(88)90592-1.

[18] N. Kojima et al., «Analysis of impurity diffusion from tunnel diodes and optimization for operation in tandem cells», Solar Energy Materials and Solar Cells, vol. 50, núm. 1, p. 237-242, gen. 1998, doi: 10.1016/S0927-0248(97)00153-0.

[19] T. Takamoto, M. Yumaguchi, E. Ikeda, T. Agui, H. Kurita, i M. AlJassim, «Mechanism of $\mathrm{Zn}$ and Si diffusion from a highly doped tunnel junction for InGaP/GaAs tandem solar cells», Journal of Applied Physics, vol. 85, núm. 3, p. 1481-1486, gen. 1999, doi: 10.1063/1.369278.

[20] P. Enquist, J. A. Hutchby, i T. J. de Lyon, «Growth and diffusion of abrupt zinc profiles in gallium arsenide and heterojunction bipolar transistor structures grown by organometallic vapor phase epitaxy», Journal of Applied Physics, vol. 63, núm. 9, p. 4485, ago. 1998, doi: 10.1063/1.340143.

[21] I. Tobías i A. Luque, «Ideal efficiency of monolithic, seriesconnected multijunction solar cells», Progress in Photovoltaics: Research and Applications, vol. 10, núm. 5, p. 323-329, ago. 2002, doi: 10.1002/pip.427.

[22] T. Takamoto, M. Yumaguchi, E. Ikeda, T. Agui, H. Kurita, i M. AlJassim, «Mechanism of $\mathrm{Zn}$ and Si diffusion from a highly doped tunnel junction for InGaP/GaAs tandem solar cells», Journal of Applied Physics, vol. 85, núm. 3, p. 1481-1486, gen. 1999, doi: 10.1063/1.369278.
(C) 2020 IEEE. Personal use of this material is permitted. Permission from IEEE must be obtained for all other uses, in any current or future media, including reprinting/republishing this material for advertising or promotional purposes, creating new collective works, for resale or redistribution to servers or lists, or reuse of any copyrighted component of this work in other works. 